\title{
An Optimization Model for Port Service Network of Refrigerated Containers Based on Transportation Time Reliability
}

\author{
Xiangqun Song, Qianli Ma, Wenyuan Wang, and Shibo Li
}

\begin{abstract}
In order to develop the transshipment and processing capacity of port nodes in the container port service network and meet the increasing demand for cold chain logistics transportation, container flow quantity should be reasonably distributed in port nodes which undertake functions of transportation and transfer in the cold chain. Through the study of refrigerated container service network, this paper establishes an optimization model for port service network of refrigerated container with minimizing the total cost as the objective, transportation time reliability and storage capacity of the refrigerated container in port nodes as constraints to achieve the optimal container flow allocation in transshipment ports under different supply and demand quantity.
\end{abstract}

Index Terms-Port service network, transportation time reliability, storage capacity, refrigerated containers

\section{INTRODUCTION}

In the global shipping market, getting the right goods at the right time and place is as important as reducing costs. In order to meet the high level of requirement of food transportation, cold chain logistics has gained rapid development in the past few years. Refrigerated containers play an increasingly important role in the cold chain logistics because of its advantages of flexibility in loading and unloading, stability in goods transport temperature and low pollution. At present, the refrigerated container transportation is mainly based on maritime transportation and chooses transshipment port for affiliation in the process of ocean transportation according to loading, unloading and transshipment requirements, thus forming the large shipping network with ports as nodes and multi parallel routes. The optimization of multi routes and ports has attracted the interest of many scholars, such as optimization problems aimed at port container transportation demand segmentation [1], optimal transportation route design problems between seaports and hinterland ports [2], optimal transport mode combination problems of multimodal container transportation [3], allocation optimization problems of multimodal container transportation [4]; heuristic algorithm [5], ant colony algorithm [6] and etc. are applied in the course of the study to solve the optimization model.

Since the quality of cargo is sensitive to time and

Manuscript received July 21, 2016; revised October 23, 2016.

Xiangqun Song, Qianli Ma, Wenyuan Wang and Shibo Li are with Dalian University of Technology, Dalian City, Liaoning Province, China (e-mail: sxqun@126.com, qianlima@mail.dlut.edu.cn, wangwenyuan@dlut.edu.cn. temperature, when the temperature get control, time reliability can be decisive to evaluate the efficiency of cold chain logistics. Domestic and foreign researchers have conducted a lot of research in the past which can be primarily divided into two aspects. The first aspect is the evaluation and calculation method of time reliability. For example, Chang J. S. [7] defined time reliability as the difference between actual arrival time and schedule time, Liang C. Y. [8] established the time reliability calculation model from two aspects of the running time and the waiting time, and Namazi-Rad M. R. [9] introduced time window to evaluate the reliability, Jong G. D. [10] took the method of preference survey to assess the transportation time reliability. The second aspect is the optimization problems constrained by time reliability. Yao B. [11] took the influence of the travel time randomness on the reliability into consideration and proposed optimization model of public transport network, and $\mathrm{Xu}$ Wangtu [12] took arrival time reliability as main constraint to solve maximum transport capacity of freight network. Most of the existing studies take point-to-point single transport line as the object to research its time reliability, but less researchers take into account that transportation time uncertainty of each line in the different stage impacts the reliability of the whole transportation network. On the other hand, refrigerated containers must get into specialized refrigerated slots for storage after arriving at the port, so storage capacity of refrigerated containers of the port has important influence on the assignment of transport quantity. In the current study, the method of fixed value [13] or statistical data analysis [14] is used to determine the port capacity constraints, and the uncertainty of port capacity is not considered. In view of the above analysis, this paper will divide the transport process of each route into three stages: maritime transportation, transfer work, and following maritime transportation, considering the effects of transportation time randomness of each stage on the time reliability of the whole shipping transportation network and random variable to describe the port's storage capacity of the refrigerated container, and finally establish an optimization model for port service network of refrigerated containers to ensure the optimal transport quantity of each route.

\section{PROBLEM DESCRIPTION AND MODELING}

\section{A. Problem Description}

Shown in Fig. 1, a number of refrigerated containers need to be transported overseas from several starting ports-SP to several destination ports-DP while there are a number of 
transshipment ports-TP that can bear the task of transferring refrigerated containers between starting ports and destination ports. Transshipment ports are divided into two types: one is transshipment port without cargo demand and the other is transshipment port with some little cargo demand. When refrigerated containers from starting ports arrive at a transshipment port, they are divided into two parts: one part is the refrigerated containers that the transshipment port demands and then will be shipped from the port to the hinterland; the other part is the refrigerated containers for transferring and will enter the refrigerated container yard for storage and be shipped by the transshipment port to the destination ports afterwards. Due to the difference in cold chain infrastructure of transshipment ports such as refrigerated container yard area and specialized reefer plugs, the storage capacity of refrigerated container of different transshipment ports is different. In consideration of the randomness of yard use, storage capacity is denoted by random variables. In addition, the transportation cost between various ports, the failure quality cost of cargo in the transport process, the carbon emission cost and the loading or unloading cost of transshipment ports are different. The transportation time between each port and the storage time of the refrigerated container at each transshipment port are both random variables.

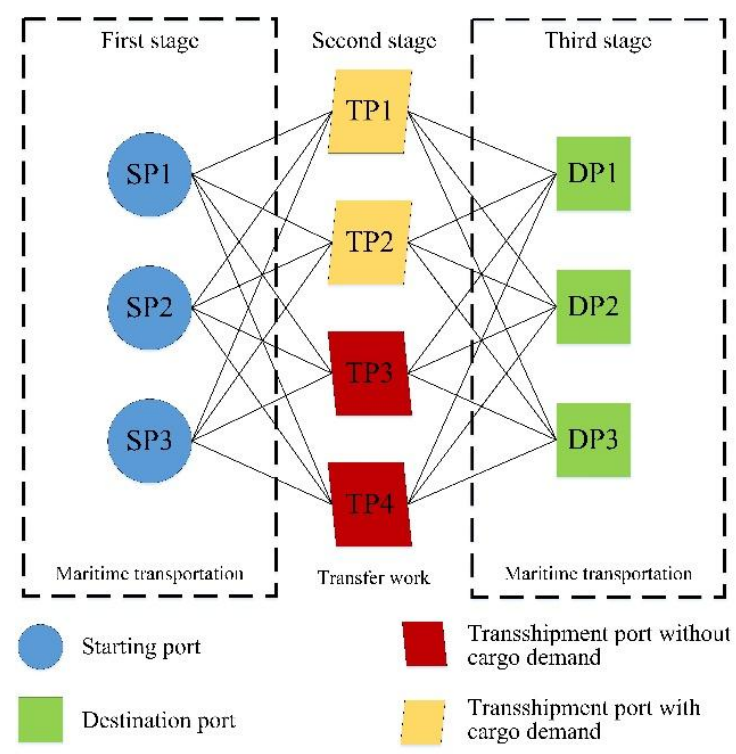

Fig. 1. Sketch map of port service network.

\section{B. Hypothesis of the Model}

1) Considering that the requirement of transportation time in cold chain logistics is higher, it is specified that the refrigerated container only be transshipped once in the process of transportation.

2) Assuming that the transportation cost between different ports, the failure quality cost of cargo in the transportation process are known.

3) Due to the short storage time of the refrigerated container in transshipment ports, the storage cost and electricity cost in transshipment ports is not considered, the cargo quality loss during handling is also not taken into account.

\section{Symbols and Concept Description}

\section{1) The decision variables}

The decision variables are shown in Table I.

TABLE I: DECISION VARIABLES

\begin{tabular}{|c|l|}
\hline Decision variable & \multicolumn{2}{|c|}{ Description } \\
\hline \multirow{4}{*}{$q_{i j}$} & $\begin{array}{l}\text { The transport quantity of the refrigerated } \\
\text { container from starting port } \mathrm{SPi} \text { to } \\
\text { transshipment port TPj (unit : TEU), } i \in S P, \\
j \in T P D \bigcup T P N\end{array}$ \\
\hline \multirow{2}{*}{$q_{j k}$} & $\begin{array}{l}\text { The transport quantity of the refrigerated } \\
\text { container from transshipment port TPj to } \\
\text { destination port DPk (unit : TEU), } \\
j \in T P D \bigcup T P N, k \in D P\end{array}$ \\
\hline
\end{tabular}

\section{2) The parameters}

Some relative parameters are shown in Table II.

\begin{tabular}{|c|c|}
\hline Parameter & Description \\
\hline$S P$ & The set of all starting ports \\
\hline$T P D$ & $\begin{array}{l}\text { The set of all transshipment ports with cargo } \\
\text { demand }\end{array}$ \\
\hline$T P N$ & $\begin{array}{l}\text { The set of all transshipment ports without cargo } \\
\text { demand }\end{array}$ \\
\hline$D P$ & The set of all destination ports \\
\hline$Q_{i}$ & $\begin{array}{l}\text { The total supply quantity of the refrigerated } \\
\text { container shipped from starting port SPi (unit : } \\
\text { TEU), } i \in S P\end{array}$ \\
\hline$P_{j}(\omega)$ & $\begin{array}{l}\text { The storage capacity of the refrigerated container } \\
\text { at transshipment port TPj (unit : TEU), which is a } \\
\text { random variable, } \quad j \in T P D \cup T P N\end{array}$ \\
\hline$S_{j}$ & $\begin{array}{l}\text { The demand of the refrigerated container at } \\
\text { transshipment port with cargo demand TPj (unit : } \\
\text { TEU), } j \in T P D\end{array}$ \\
\hline$t_{m t}^{i j}(\omega)$ & $\begin{array}{l}\text { The maritime transportation time of the } \\
\text { refrigerated container from starting port SPi to } \\
\text { transshipment port TPj (unit : day), which is a } \\
\text { random variable, } i \in S P, \quad j \in T P D \cup T P N\end{array}$ \\
\hline$t_{d}^{j}(\omega)$ & $\begin{array}{l}\text { The storage time of the refrigerated container at } \\
\text { transshipment port } \mathrm{TPj} \text { (unit : day), which is a } \\
\text { random variable, } \quad j \in T P D \bigcup T P N\end{array}$ \\
\hline$T$ & $\begin{array}{l}\text { The specified transportation time of the } \\
\text { refrigerated container (unit: day) }\end{array}$ \\
\hline$d_{i j}$ & $\begin{array}{l}\text { The transportation distance from starting port SPi } \\
\text { to transshipment port TPj (unit : KM), } i \in S P \\
j \in T P D \bigcup T P N\end{array}$ \\
\hline$d_{j k}$ & $\begin{array}{l}\text { The transportation distance from transshipment } \\
\text { port TPj to destination port DPk (unit : KM), } \\
j \in T P D \bigcup T P N, k \in D P\end{array}$ \\
\hline$\xi_{i j}$ & $\begin{array}{l}\text { The transportation cost of the refrigerated } \\
\text { container from starting port SPi to transshipment } \\
\text { port TPj (unit : yuan/TEU.KM), } i \in S P \text {, } \\
j \in T P D \bigcup T P N\end{array}$ \\
\hline$\xi_{j k}$ & $\begin{array}{l}\text { The transportation cost of the refrigerated } \\
\text { container from starting port TPj to transshipment } \\
\text { port DPk (unit : } \quad \text { yuan/TEU.KM), } \\
j \in T P D \cup T P N, k \in D P\end{array}$ \\
\hline$\psi_{i j}$ & $\begin{array}{l}\text { The failure quality cost of cargo in the } \\
\text { transportation process from starting port SPi to } \\
\text { transshipment port TPj (unit : yuan/TEU.KM), } \\
i \in S P, \quad j \in T P D \cup T P N\end{array}$ \\
\hline$\psi_{j k}$ & $\begin{array}{l}\text { The failure quality cost of cargo in the } \\
\text { transportation process from transshipment port TPj } \\
\text { to destination port DPk (unit : yuan/TEU.KM), } \\
j \in T P D \bigcup T P N, \quad k \in D P\end{array}$ \\
\hline
\end{tabular}




\begin{tabular}{|c|c|}
\hline$F_{j}$ & $\begin{array}{l}\text { The loading or unloading cost of the refrigerated } \\
\text { container at transshipment port TPj (unit : } \\
\text { yuan/TEU), } j \in T P D \bigcup T P N\end{array}$ \\
\hline$\zeta$ & The time cost of transportation per day \\
\hline$V$ & $\begin{array}{l}\text { The value of cargo in the refrigerated container } \\
\text { (unit : yuan/TEU) }\end{array}$ \\
\hline$\rho$ & $\begin{array}{l}\text { The carbon emission cost in the transportation } \\
\text { process of the refrigerated container (unit : } \\
\text { yuan/TEU } \cdot \mathrm{KM} \text { ) }\end{array}$ \\
\hline$\alpha$ & $\begin{array}{l}\text { The specified reliability level of the transportation } \\
\text { time of the port service network }\end{array}$ \\
\hline$\beta$ & The confidence level \\
\hline
\end{tabular}

3) Conception description

The transportation time reliability of the port service network is defined as the probability that the mean transportation time of the refrigerated container of all the routes in the network is less than the specified transportation time. The mean transportation time is the ratio of total transportation time to total container quantity, which is calculated by the sum of all stages of transportation.

$$
\begin{aligned}
\text { Mean time }= & \frac{\sum_{i \in S P} \sum_{j \in T P D \cup T P N} q_{i j} t_{m t}^{i j}(\omega)}{\sum_{i \in S P} \sum_{j \in T P D \cup T P N} q_{i j}} \\
& +\frac{\sum_{j \in T P D \cup T P N} \sum_{k \in D P} q_{j k}\left(t_{m t}^{j k}(\omega)+t_{d}^{j}(\omega)\right)}{\sum_{j \in T P D \cup T P N} \sum_{k \in D P} q_{j k}}
\end{aligned}
$$

D. Optimization Model

4) Objective function

$$
\begin{aligned}
\min \mathrm{Z} & =\left\lfloor\sum_{i \in S P} \sum_{j \in T P D \cup T P N} \xi_{i j} d_{i j} q_{i j}+\sum_{j \in T P D \cup T P N} \sum_{k \in D P} \xi_{j k} d_{j k} q_{j k}\right\rfloor \\
& +\left[\sum_{i \in S P} \sum_{j \in T P D \cup T P N} \psi_{i j} d_{i j} q_{i j}+\sum_{j \in T P D \cup T P N} \sum_{k \in D P} \psi_{j k} d_{j k} q_{j k}\right] \\
& +\left[\sum_{i \in S P} \sum_{j \in T P D \cup T P N} q_{i j} F_{j}+\sum_{j \in T P D \cup T P N} \sum_{k \in D P} q_{j k} F_{j}\right] \\
& +E\left\{\left[\sum_{i \in S P} \sum_{j \in T P D \cup T P N} t_{m t}^{i j}(\omega) q_{i j}+\sum_{j \in T P D \cup T P N} \sum_{k \in D P}\left(t_{m t}^{j k}(\omega)+t_{d}^{j}(\omega)\right) q_{j k}\right] V \zeta\right\} \\
& +\left(\sum_{i \in S P} \sum_{j \in T P D \cup T P N} q_{i j} d_{i j} \rho+\sum_{j \in T P D \cup T P N} \sum_{k \in D P} q_{j k} d_{j k} \rho\right)
\end{aligned}
$$

5) Constraints

$$
\begin{gathered}
\operatorname{Pr}\left(\frac{\sum_{i \in S P} \sum_{j \in T P D \cup T P N} q_{i j} t_{m t}^{i j}(\omega)}{\sum_{i \in S P} \sum_{j \in T P D \cup T P N} q_{i j}}+\frac{\sum_{j \in T P D \cup T P N} \sum_{k \in D P} q_{j k}\left(t_{m t}^{j k}(\omega)+t_{d}^{j}(\omega)\right.}{\sum_{j \in T P D \cup T P N} \sum_{k \in D P} q_{j k}}\right. \\
\left.\forall j \in T P D \bigcup T P N, \operatorname{Pr} \mid \sum_{k \in D P} q_{j k}<P_{j}(\omega)\right)>\beta \\
\forall j \in T P D, \sum_{i \in S P} q_{i j}=\sum_{k \in D P} q_{j k}+S_{j} \\
\forall j \in T P N, \sum_{i \in S P} q_{i j}=\sum_{k \in D P} q_{j k} \\
Q_{i}=\sum_{j \in T P D \cup T P N} q_{i j} \\
q_{i j} \geq 0, q_{j k} \geq 0
\end{gathered}
$$

In the above model Eq.(1) is the objective function, which is composed of five parts. The first one is the total transportation cost of the refrigerated containers, the second one is the total failure quality cost of cargo, the third one is the total loading and unloading cost of the refrigerated containers at transshipment ports, the fourth one is the total time cost of transportation of refrigerated containers, which is expressed in the form of mathematical expectation due to the presence of random variables, the fifth one is the total carbon emission cost in the transportation process of the refrigerated containers. Eq.(2) Eq.(7) are the constraints. Eq.(2) indicates that the transportation time reliability of the port service network should meet the requirement. Eq.(3) indicates that the probability that the quantity of refrigerated container transferred by transshipment port TPj is in the storage capacity range of $\mathrm{TPj}$ is greater than the confidence level. Eq.(4) indicates that for transshipment port with cargo demand, the quantity of the refrigerated container transported to the port is divided into demand quantity and transfer quantity. Eq.(5) indicates that for transshipment port without cargo demand, the quantity of the refrigerated container transported to the port is equal to transfer quantity. Eq.(6) indicates that the sum of the quantity of the refrigerated container transported from each starting port to each transshipment port is equal to the total supply quantity. Eq.(7) indicates the nonnegative constraint of the variables.

\section{EXAMPLE ANALYSIS}

A starting port SP in America will transport a batch of 20 feet standard refrigerated containers to a destination port DP in China, three transshipment ports TP1, TP2, TP3 can be selected to provide transshipment work. Each refrigerated container is loaded with 10 tons of cargo, the value of that is 500 thousand yuan. According to the carbon tax of 20 yuan per ton, the carbon emission cost is calculated as 0.017 yuan/TEU.KM. On the basis of the bank's annual interest of $1 \%$, the time cost of transportation of refrigerated containers is calculated as 13.89 yuan/TEU $\cdot$ day. The specified 
transportation time of the refrigerated container is 20 days; the specified reliability level of the transportation time of the port service network is 0.95 ; the confidence level is 0.9 . It is assumed that all of the time parameters obey normal distribution, and the storage capacity of the refrigerated container at transshipment port obeys uniform distribution. The relevant parameters of the transshipment ports are shown in Table III, and other transport parameters are shown in Table IV.

TABLE III: RELEVANT PARAMETERS OF TRANSSHIPMENT PORT

\begin{tabular}{|c|c|c|c|c|}
\hline Transshipment port & $\begin{array}{c}\text { Cargo } \\
\text { demand(TEU) }\end{array}$ & $\begin{array}{c}\text { Loading or unloading cost of } \\
\text { refrigerated container(yuan/TEU) }\end{array}$ & $\begin{array}{c}\text { Storage capacity of refrigerated } \\
\text { container(TEU) }\end{array}$ & $\begin{array}{c}\text { Storage time of } \\
\text { refrigerated container(day) }\end{array}$ \\
\hline TP1 & 300 & 450 & $\mathrm{U}(1000,1800)$ & $\mathrm{N}(2.5,0.5)$ \\
\hline TP2 & 400 & 550 & $\mathrm{U}(1500,2500)$ & $\mathrm{N}(2,0.5)$ \\
\hline TP3 & 500 & 500 & $\mathrm{U}(2000,3000)$ & $\mathrm{N}(3,1)$ \\
\hline
\end{tabular}

TABLE IV: TRANSPORTATION PARAMETERS

\begin{tabular}{|c|c|c|c|c|}
\hline Transportation route & $\begin{array}{c}\text { Transportation cost of } \\
\text { refrigerated } \\
\text { container }(\text { yuan/TEU } \cdot \mathrm{KM})\end{array}$ & $\begin{array}{l}\text { Failure quality cost of } \\
\text { cargo (yuan/TEU } \cdot \mathrm{KM})\end{array}$ & $\begin{array}{l}\text { Transportation } \\
\text { distance (KM) }\end{array}$ & Transportation time(day) \\
\hline $\mathrm{SP} \rightarrow \mathrm{TP} 1$ & 4.0 & 0.7 & 5300 & $\mathrm{~N}(11,2)$ \\
\hline $\mathrm{SP} \rightarrow \mathrm{TP} 2$ & 3.5 & 0.8 & 5400 & $\mathrm{~N}(11.5,2)$ \\
\hline $\mathrm{SP} \rightarrow \mathrm{TP} 3$ & 3.5 & 0.4 & 4600 & $\mathrm{~N}(9.5,1.5)$ \\
\hline $\mathrm{TP} 1 \rightarrow \mathrm{DP}$ & 3.0 & 1.2 & 1100 & $N(3,1)$ \\
\hline $\mathrm{TP} 2 \rightarrow \mathrm{DP}$ & 2.0 & 1.1 & 1200 & $\mathrm{~N}(3.5,1)$ \\
\hline $\mathrm{TP} 3 \rightarrow \mathrm{DP}$ & 2.5 & 1.5 & 2100 & $\mathrm{~N}(5,1.5)$ \\
\hline
\end{tabular}

The allocation of transport quantities of refrigerated containers from starting port SP to destination port DP is calculated under five different supply quantities (4000TEU, 5000TEU, 6000TEU, 7000TEU, 8000TEU). The model is solved using MATLAB. The result can be found in Table V and the allocation map of transport quantities can be found in Fig. 2.

TABLE V: CALCULATION RESULTS - ALLOCATION OF TRANSPORT QUANTITIES

\begin{tabular}{|l|c|c|c|c|c|c|}
\hline $\begin{array}{l}\text { Route } \\
\begin{array}{l}\text { Tota } \\
\text { supply } \\
\text { quantity( } \\
\text { EU) }\end{array}\end{array}$ & $\begin{array}{c}\mathrm{SP} \rightarrow \mathrm{T} \\
\mathrm{P} 1\end{array}$ & $\begin{array}{c}\mathrm{SP} \rightarrow \mathrm{T} \\
\mathrm{P} 2\end{array}$ & $\begin{array}{c}\mathrm{SP} \rightarrow \mathrm{T} \\
\mathrm{P} 3\end{array}$ & $\begin{array}{c}\mathrm{TP} 1 \rightarrow \\
\mathrm{DP}\end{array}$ & $\begin{array}{c}\mathrm{TP} 2 \rightarrow \\
\mathrm{DP}\end{array}$ & $\begin{array}{c}\mathrm{TP} 3 \rightarrow \\
\mathrm{DP}\end{array}$ \\
\hline 4000 & & & & & & \\
\hline 5000 & 300 & 1128 & 2572 & 0 & 728 & 2072 \\
\hline 6000 & 300 & 2300 & 3400 & 0 & 1900 & 2900 \\
\hline 7000 & 800 & 2800 & 3400 & 500 & 2400 & 2900 \\
\hline 8000 & 1800 & 2800 & 3400 & 1500 & 2400 & 2900 \\
\hline
\end{tabular}

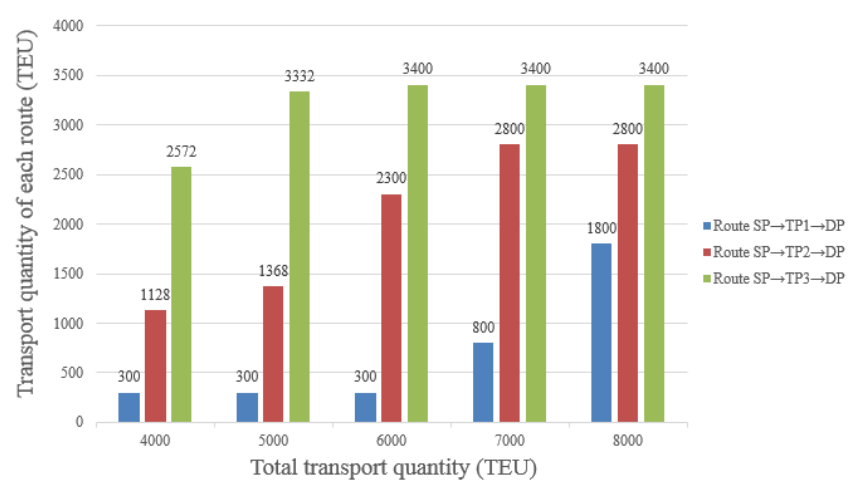

Fig. 2. Allocation map of transport quantities.

According to the results, when the total supply quantity increases from $4000 \mathrm{TEU}$ to $6000 \mathrm{TEU}$, the transport quantity of route $\mathrm{SP} \rightarrow \mathrm{TP} 3 \rightarrow \mathrm{DP}$ increases fastest while the transport quantity of route $\mathrm{SP} \rightarrow \mathrm{TP} 1 \rightarrow \mathrm{DP}$ is invariant, as shown in Tab.3. The cause for the occurrence is that the route at a lower cost is chosen in the first place. Meanwhile, route $\mathrm{SP} \rightarrow \mathrm{TP} 2 \rightarrow \mathrm{DP}$ shares part of the transport quantity as a result of the long transport time of route $\mathrm{SP} \rightarrow \mathrm{TP} 3 \rightarrow \mathrm{DP}$ which makes it fail to meet the requirements of the time reliability of service network. When the total transport quantity increases from $6000 \mathrm{TEU}$ to $7000 \mathrm{TEU}$, the transport quantity of route $\mathrm{SP} \rightarrow \mathrm{TP} 3 \rightarrow \mathrm{DP}$ reaches upper limit, which is restrained by the storage capacity of refrigerated container at transshipment port TP3.

\section{CONCLUSION}

The optimization for cold chain service network which regards ports as nodes has been an advanced and significant research. Reasonable arrangements of the transport quantity of refrigerated container among the ports can not only improve transport efficiency through giving full play to the handling capacity of ports but also save cost through solving congestion and demurrage problems. This paper builds an optimization model for port service network of refrigerated container in order to give a reasonable arrangement of the transport flow quantity of refrigerated container among the ports. The result of the study can provide reference for the design of refrigerated container transport route and the construction of transshipment ports.

Same as other studies, this paper makes some assumptions and ignores part of the influencing factors in the research process, therefore following study is required. The other factors such as the influence of changing transport ships at transshipment ports or failure quality of cargo in the process of loading and unloading refrigerated containers should be considered to make the model more complete and reasonable.

\section{ACKNOWLEDGMENT}

The authors would like to acknowledge the support of National Natural Science Foundation of China (No. 51309049 and No. 51279026).

\section{REFERENCES}


[1] C. C. Chou, F. T. Kuo, R. H. Gou et al., "Application of a combined fuzzy multiple criteria decision making and optimization programming model to the container transportation demand split," Applied Soft Computing, vol. 10, no. 4, pp. 1080-1086, 2010.

[2] K. Braekers, C. An, and G. K. Janssens, "Optimal shipping routes and vessel size for intermodal barge transport with empty container repositioning," Computers in Industry, vol. 64, no. 2, pp. 155-164, 2013 .

[3] C. Hao and Y. Yue, "Optimization on combination of transport routes and modes on dynamic programming for a container multimodal transport system," Procedia Engineering, vol. 137, pp. 382-390, 2016.

[4] M. Arnone, S. Mancini, and A. Rosa, "Formulating a mathematical model for container assignment optimization on an intermodal network is," Procedia - Social and Behavioral Sciences, vol. 111, no. 3, pp. 1063-1072, 2014.

[5] J. He, Y. Huang, and D. Chang, "Simulation-based heuristic method for container supply chain network optimization is," Advanced Engineering Informatics, vol. 29, no. 3, pp. 339-354, 2015.

[6] S. Xiang-Qun, Z. Peng, and G. Z. Jian, "Ant colonies optimization for containers transportation network system of seaports," Journal of Dalian University of Technology, vol. 47, no. 6, pp. 853-857, 2007.

[7] J. S. Chang, "Assessing travel time reliability in transport appraisal," Journal of Transport Geography, vol. 18, no. 3, pp. 419-425, 2010.

[8] C. Y. Liang and L. L. Li, "Research on evaluation method for the service quality of public transport based on time reliability degree," Applied Mechanics and Materials, vol. 361-363, pp. 2205-2209, 2013.

[9] M. R. Namazi-Rad, M. Dunbar, H. Ghaderi et al., "Constrained optimization of average arrival time via a probabilistic approach to transport reliability," Plos One, vol. 10, no. 5, pp. 1-15, 2015.

[10] G. D. Jong, M. Kouwenhoven, J. Bates et al., "New SP-values of time and reliability for freight transport in the Netherlands," Transportation Research Part E Logistics \& Transportation Review, vol. 64, no. 2, pp.71-87, 2014.

[11] B. Yao, P. Hu, X. Lu et al., "Transit network design based on travel time reliability," Transportation Research Part C Emerging Technologies, vol. 43, pp. 233-248, 2014.

[12] W. T. Xu, S. S. Yu, and S. W. He, "Calculation of capacity of the express freight transportation service network under constraint of delivery time," Journal of the China Railway Society, vol. 35, no. 5, pp. 8-14, 2013

[13] S. L. Lam and Y. Gu, "A market-oriented approach for intermodal network optimisation meeting cost, time and environmental requirements," International Journal of Production Economics, 2016.

[14] H. Maučec, A. Ogorelc, R. Zelenika et al., "Optimizing Overseas Container Transportation: A case involving Transatlantic Ports[J]," Proceedings of the Institution of Mechanical Engineers Part $M$ Journal of Engineering for the Maritime Environment, vol. 229, no. 3 , pp.1-11, 2013.

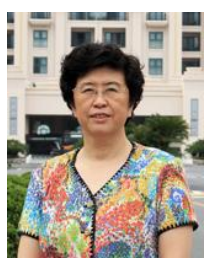

Xiangqun Song was born in Dalian city, Liaoning province, China, in 1959. She received the bachelor degree of harbor, waterway and coastal engineering in 1982 and the master degree of harbor, waterway and coastal engineering in 1987 from Dalian University of Technology, Dalian City, Liaoning Province, China.

From 1993 to 2007, she was an associate professor at the Faculty of Infrastructure Engineering, Dalian University of Technology. Since 2007, she is a professor at the Faculty of Infrastructure Engineering, Dalian University of Technology, Dalian City, Liaoning Province, China. Her research interests include port planning and layout, port transportation planning, structural optimization of harbor works.

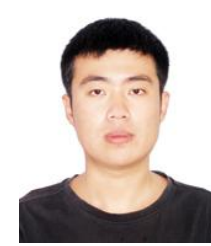

Qianli Ma was born in Xinxiang city, Henan province, China, in 1989. He received the Bachelor degree of harbor, waterway and coastal engineering in 2013 from Dalian University of Technology, Dalian City, Liaoning Province, China. Currently, he is a doctoral student at the Research Center for Port Development, Faculty of Infrastructure Engineering, Dalian University of Technology.

His research interests include cold chain logistics, port planning and layout, cold chain transportation planning.

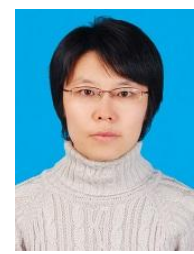

Wenyuan Wang was born in Fuxin city, Liaoning province, China, in 1984. She received the Bachelor degree of harbor, waterway and coastal engineering in 2006, the master degree of harbor, coastal and offshore engineering in 2008, and the Ph.D. degree of harbor, coastal and offshore engineering in 2012 from Dalian University of Technology, Dalian city, Liaoning Province, China.

From 2012 to 2014, she was a postdoctoral researcher at the Faculty of Infrastructure Engineering, Dalian University of Technology. Since 2014, she is a lecturer at the Faculty of Infrastructure Engineering, Dalian University of Technology. Her research interests include port planning and layout, port transportation planning.

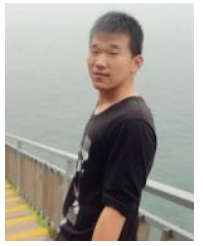

Shibo Li was born in Anshan city, Liaoning province, China, in 1992. He received the bachelor degree of harbor, waterway and coastal engineering in 2015 from Dalian University of Technology, Dalian city, Liaoning province, China. Currently, he is a graduate student at the Research Center for Port Development, Faculty of Infrastructure Engineering, Dalian University of Technology.

His research interests include cold chain logistics,

port planning and layout. 